DOI: $10.17805 /$ zpu.2019.1.6

\title{
Философские проблемы естествознания: поиск новых условий понятности опыта
}

\author{
С. В. ОБОЛКИНА \\ ИНСТИТУТ ФИЛОСОФИИ И ПРАВА УРАЛЬСКОГО РЕГИОНАЛЬНОГО ОТДЕЛЕНИЯ \\ РОССИЙСКОЙ АКАДЕМИИ НАУК
}

В работе анализируется научный и философский потенциал дисциплины «Философские проблемы естествознания». Предполагаемая по умолчанию связь между философией и естествознанием в подавляющем большинстве случаев мыслится в категориях иерархического выстраивания отношений «попечения». Автор показывает проблематичность такого понимания и на материале эпистемологических исследований выявляет проблему, лежащую в основаниях подобных решений. Она связана с некорректным пониманием онтологии и, соответственно, онтологических оснований естествознания. Предлагая видеть онтологию принципиально не тождественной понятиям «картина мира», “образ реальности» и т. п., автор основывается на традиции отечественной философии: в работах М. К. Мамардашвили, В. В. Бибихина и других ученых онтология выступает условиями понятности опыта. Этот подход близок поискам в современной философии, которая активно обращается к онтологической проблематике в контексте исследования научного знания (К. Мейясу, Г. Харман, Э. Пикеринг и др.).

Автор анализирует формирование классической матрицы онтологии, ее влияние на становление естествознания и пределы, ею накладываемые. Единство философии и естествознания предлагается увидеть именно в этом ключе понимания онтологии. В качестве примера анализируется теория великого объединения. Также в работе уделяется значительное внимание основаниям дифференциации философии и науки. Единое пространство познания мира трактуется как коммуникативное, в пределах которого особенно важны спецификация, различение. Автор предлагает рассматривать его как систему габитусов языка: это не просто формы дифференциации, но в первую очередь различный когнитивный инструментарий. 
Данный подход допускает возможность дифференциации науки и философии как различных форм познания без потери их фундаментального единства. Сегодня это единство проявляется и в форме кризиса миропонимания.

Ключевые слова: философия науки; естествознание; эпистемология; онтология; онтологический поворот; спекулятивный реализм; габитусы языка; условия понятности

\section{ВВЕАЕНИЕ}

$\Phi$ илософские проблемы естествознания предполагают обращение к онтологическому, гносеологическому, аксиологическому, методологическому и т. п. аспектам естественных наук в максимальной близости к их предметному содержанию. По умолчанию это подразумевает наличие связи между философией и естествознанием.

Типология эпистемологических позиций помогает нам удерживать в поле зрения многообразие вариантов понимания этой связи: например, это выделяемые С. А. $\Lambda$ ебедевым трансценденталистский (метафизический), позитивистский и диалектический подходы (Иебедев, 2013: 12-36). Но типологический анализ, по сути, дает нам лишь понимание того, что проблемы в этом вопросе были, есть и будут. Одна из них обнаруживает себя даже в самой формулировке дисциплины.

Как интерпретировать подчинительную связь в словосочетании «философские проблемы естествознания»: у естествознания возникают проблемы, которые могут быть решены философией, или философия должна рассматривать какие-то проблемы естествознания в качестве своих собственных?

Аля философии и сегодня привычен первый вариант интерпретации - то есть ситуация философской «заботы и попечения» по отношению к науке. Например, А. Розенберг считает: «...философия имеет дело с двумя наборами вопросов: во-первых, вопросы о том, что наука - физическая, биологическая, социальная, поведенческая не может ответить сейчас и, возможно, никогда не сможет ответить. Во-вторых, вопросы о том, почему науки не могут ответить на первую партию вопросов» (Rosenberg, 2005: 4). Многие мыслители вслед за А. Койре, развивающим позицию Э. А. Берта (Койре, 1985: 13), видят в философии функцию «строительных лесов» для возведения здания новой науки, в том числе науки о сложности (так называемой теории complexity). Трудно не согласиться с ощущением, что у этой надежды есть все основания. Но проблема в том, что исследователи не поясняют, почему же философия может иметь дело с таким уровнем фундаментальных представлений о мире. По умолчанию используется статус философии как знания «более фундаментального», «старшего», «обобщающего». Но мы понимаем, что сам по себе статус может быть просто отброшен: в свое время, будучи «молодым бунтарем», позитивистский дискурс отказался принять эту традицию уважения к старшинству. Позитивизм породили не ученые, это были философы, которые просто «делали свою работу»: они не нашли для идеи «старшинства» философии валидной аргументации. Однако благодаря этому «бунту» мысль о взаимоотношениях философии и науки попала в некий замкнутый круг. П. Мачамер (Р. Machamer) показывает путь этой мысли: естествознание и его метод в годы своего блистательного развития становятся образцовыми для всякого познания. Тем самым иерархические отношения «заботы и попечения» перевернулись, но сама иерархическая «матрица» лишь укрепилась, и теперь философия, дерзающая сохранять связь с научным знанием, оказалась «под присмотром» науки. Несмотря на то что такой ответ довольно быстро вызвал разочарование, разговор о связи философии и науки не вышел из позитивистской матрицы: «Практически все 
основные последующие шаги, меняющие характер философии науки, были инициированы самими оригинальными позитивистами. Эта непрерывность не была отмечена теми, кто прославился в течение следующих десятилетий, хотя они видели себя революционными и яростно антипозитивистскими» (Machamer, 2002: 6).

Обоснование связи философии и естествознания, которая бы избегала направляющих обозначенной иерархической матрицы, является задачей данной статьи. В работе предлагается мысль о том, что онтологическое измерение выступает основой единства науки и философии, а также обусловливает их эволюцию. Однако это единство не исключает наличие условий, перманентно поддерживающих гетерогенность философии и науки. Предлагается рассмотреть в качестве агента дифференциации габитусы языка, поскольку тот или иной габитус выступает особым когнитивным инструментарием.

\section{ОНТОАОГИЯ КАК УСАОВИЯ ПОНЯТНОСТИ ОПЫТА}

Почему же позитивизм лишь укрепил ту оптику рассмотрения связи философии и науки, один из результатов которой (о главенстве философии) отвергал? Аумается, стоит обратить внимание на своего рода онто-гносеологическую «спутанность» в основании позитивистского решения. Естествознание (в облике физики) высоко ценилось позитивистами именно гносеологически - как метод и характер истины. Явно или неявно, но это уважение становилось убеждением о том, что естественнонаучные теории о мире выступают онтологией этого мира. Естественно, рано или поздно вставал вопрос: зачем хранить весь философский онтологический багаж, если мы имеем вполне продвинутую научную картину мира? Разве метафизические измышления какого-нибудь древнего грека могут соперничать в объяснении мира с блистательными прорывами физики? Почему бы не «отметить» роль философии в формировании картины мира, оставив ей роль блюстителя чистоты методов и/или высказываний? Что и было сделано.

Проблема этой позиции заключается в том, что мысль постоянно норовит проигнорировать несводимость понятий «онтология» и «картина мира». «Бытие», «сущее», «существующее», «реальность», «мир» и т. п. - не синонимы. Это смешение допустимо для повседневного языка, но не для философии - хотя для английского языка, к примеру, такое различение выступает не самой простой задачей, поскольку «бытие» обозначается как «being», а «сущее» передается всего лишь множественным числом (beings). Возможно, именно это обстоятельство сыграло определенную роль в том, что англоязычная философия науки в большинстве своем развивает традиции позитивизма. В любом случае, если мы не хотим крутиться по траектории мысли, проложенной англоязычной эпистемологией, то всякая мысль о важности философских оснований для естествознания и науки в целом должна быть проанализирована, во-первых, на предмет разведения гносеологического и онтологического, а во-вторых, на предмет различения онтологического и онтического (если использовать хайдеггеровскую терминологию). Или, что то же самое, вернуть онтологии ее собственность.

Современная философия очень заинтересована в этом. В первую очередь заинтересованы спекулятивный реализм и другие философы «онтологического поворота». Хотя, как ни парадоксально, для философов с этой «передовой»в большинстве своем не свойственно учитывать различие онтологического и онтического. Но они больше не смешивают гносеологическое и онтологическое - потому что такое смешение 
осуждается как «катастрофа корреляционизма». «Под “корреляцией” мы понимаем идею, согласно которой мы можем иметь доступ только к корреляции между мышлением и бытием, но никогда к чему-то одному из них в отдельности. Мы будем называть “коррелячионизмом” любое направление мысли, которое утверждает непреодолимый характер корреляции, понятой таким образом» (курсив источника. - С. О.) (Мейясу, 2015: 11). Интрига философии нового онтологического поворота по-своему честна и красива: это жажда дотронуться до самой реальности, убрать посредника в виде разума, культуры, социума и т. п. Жажда реальности, утолять которую, как полагает тот же К. Мейясу, должна наука. Поэтому он предлагает тезис «...решительно докритический - он представляет собой регрессию к “наивной” позиции догматической метафизики» (курсив источника. - C. О.) (там же: 10). Так философия ищет возможности «развязать руки» науке, чтобы та сумела постигнуть сущее. Причем очень сложное сущее - ведь парадигма сложности, нелинейности и неоднозначности, по сути, и вызвала к жизни новые онтологические решения. Не погружаясь в исследование того, что же такое онтология, эти философы тем не менее акцентируют ее значимость. Например, Э. Пикеринг, рассуждающий о попытках ученых «обуздать» Миссисипи, говорит: «Инженеры хотели выбраться из гущи вещей, найти вневременную скрытую сущность реки и, таким образом, взять над ней верх, сперва концептуально, а затем материально» (Пикеринг, 2017: 161). Он предлагает измениться онтологии: «...мы бы сознательно жили (совершенно иначе, чем живем сейчас) в потоке становления, не отрицая его» (там же: 168).

Таким образом, во-первых, уточняется «адрес» связи философии и естествознания: это онтология. Во-вторых, онтологическое в этих исследованиях мыслится не картиной мира (хотя понятийное их смешение характерно для того же Мейясу), но скорее базисом, на котором наука в принципе может выстраивать что-то свое.

Эта позиция близка тому пониманию онтологии, которую уже довольно давно развивает российская мысль. М. К. Мамардашвили, В. В. Бибихин, М. М. Бахтин и другие мыслили онтологию в первую очередь условиями понятности опыта. «Эмпирическое описание бесконечно, рассеянно; оно запутывается в переплетениях тысяч и тысяч противоречивых обстоятельств и связей. Разобрать их и увидеть внутреннюю связь невозможно, если не посмотреть глазами каких-то других предметов, которые суть теоретические конструкции. Между тем идеи и формы Платона и являются такими первичными конструкциями, коим отнюдь не приписывалось существование материальных предметов, они и есть условие их понятности» (Мамардашвили, 2002: 80-81).

К. А. Павлов пишет, что «..философия изобретает такие понятия, как “само бытие”, “само сущее”, “сами вещи”, “природа сама по себе”, “объективность” и т. п. Возникает законный вопрос: изобретая подобные понятия, не занимается ли тогда философия тем же самым, что и «частные науки»? Не конструирует ли и сама философия понятия, которые затем и изучает ? Ответ: нет. <...> Они суть регулятивныле идеи. Регулятивные идеи философии играют ограничительную, а не конструктивную (т. е. не предписательную) роль. Они задают смысл всем теоретическим видам человеческих исканий, направленных на исследование "природы вещей”, бытие которых предполагается имеющим место вне теории» (Павлов, 2009: 78-79).

И если онтология действительно выводит нас на базисные структуры миропонимания, то именно в них мы и должны обнаружить искомое основание единства философии и науки (понимаемой в данном случае преимущественно как естествознание). 
ЗА СКОБКАМИ БЫТИЯ:

\section{ОНТОАОГИЧЕСКАЯ МАТРИЦА ПАРМЕНИАА}

Обычно в поиске самых первых «точек схода» философии и естествознания мысль обращается к античной натурфилософии (реализуя логику поиска сходства картин мира). Что, во-первых, породжает тенденцию упрощения древней натурфилософии, и потому снова и снова возникает потребность анализа этих учений: например, это эпистемологическая полемика вокруг атомизма и америзма Аемокрита или вопрос о материалистичности древних учений (см., например: Аебедев, 2008; Толорайя, 1991). Во-вторых, встраивая античную натурфилософию в историю науки как ее начальный этап, мы забываем, что натурфилософия существовала и позднее, развиваясь параллельно со становлением экспериментально-математического естествознания, и особенно активно в XVIII-XIX вв. (см.: Касавин, 1998; Косарева, 1997). И наконец, поиск сходств картин мира - это именно та деталь, в которой прячется «дьявол» позитивистской слепоты в отношении онтологии. Практически незамеченной оказалась ее роль для науки в таком натурфилософском учении, в котором сходств с научной картиной мира меньше всего, - в учении Парменида. Казалось бы, не может быть и речи, чтобы выводить основание научного знания из концепции, отрицающей движение, изменение и развитие. Но это ошибка - и вновь ошибка смешения онтологии и картины мира.

Нужно сказать, Парменид «честно старался». Он дает картину мира: вторая часть его поэмы (Парменид, 1989) представляет собой пересказ одной из важнейших концепций древних фисиологов - учения о стихиях; и в нем отчетливо говорится о том, что изменение и движение есть. Но сам же Парменид настаивает, что это речи «лживые», хотя и «нарядные», и предлагает поставить под сомнение не сам факт существования изменчивости и уничтожения, но опросить само это «есть» на предмет его подлинности. Поэтому первая часть поэмы повествует о бытии («онкосе»).

«Бытие», принципиально не сводимое Парменидом к «сущему», «существующему» или «миру», выступает базисным условием понятности опыта. Онтология создает философские нарративы, главными действующими героями в которых являются отвлеченные понятия и их пары («единое / многое», «необходимое / случайное», «действительное / возможное» и т. п.). При этом благодаря парменидовскому открытию бытия была сформирована особая матрица понимания: единое, тождественное имеет приоритет перед множественностью; вечное - перед изменчивым и исчезающим и т. А.

Философский подвиг Парменида заключается в том, что он обратился к вечной подозрительности человека в отношении мира: о том, что «тут что-то не так» и что «не может быть так», что все действительно значимое - память, любовь, красота, сама жизнь - рассеивается и исчезает, словно не было. Парменид настаивает: знайте, что бытие, не причастное изменению и, следовательно, рассеиванию и протуханию, есть - в подлинном смысле этого слова. Элеаты взяли на себя аргументацию тезиса об «онкосе», которая породила полемику; взаимное отражение доводов сформировало метафизику. Однако парменидовское открытие заключалось не только в открытии, но и в сокрытии: то, что выносилось за скобки в «зону невидимости», стало предметом науки. Зона «небытия»- изменчивости, движения, обусловленности и конечности - стала нововременным обликом природы.

Такой «негативный» способ осуществления не является чем-то уникальным. Психологи и когнитивисты отмечают, какая ничтожная часть реально воспринимаемого 
«доводится» до осознанности: воспринято гораздо меньше, чем увидено и услышано; замечено меньше, чем воспринято; запомнено меньше, чем замечено. И мы всегда обнаруживаем как нечто внезапно интересное ту область, которую в свое время оставили вниманием «в тени». Естествознание постепенно заполнило ту нишу «присутствия-отсутствия», которая образовалась благодаря классической матрице онтологии.

Естествознание, однако, не только образуется, но и действует в пределах этой онтологической матрицы. В первую очередь это принцип объективации. Вводится абсолютный наблюдатель, который гарантирует невозможность самопроизвольных трансформаций, «волшебства». В науке он носит имя «пространственно-временной симметрии». Именно это, онтологическое по своему происхождению, допущение позволяет говорить о законах природы - их как бы видит этот абсолютный наблюдатель, поскольку конкретный исследователь всегда ограничен в возможностях диахронного и синхронного охвата реальности.

Кроме того, онтологические допущения Парменида проявляются и как основания исследовательской стратегии классического естествознания. Галилеевский маятник, понятие ускорения свободного падения и т. п. возникают только в ситуации «невнимания» к трению, сопротивлению воздуха и т. п. Исследователь различает некое «подлинное» состояние события и «ошибки» его осуществления, которые можно просто не видеть - это «небытие». Нужно понимать это метафизическое «наследство» в основаниях идеализаций классической науки. Сейчас они видятся довольно грубыми, но без них естествознание бы не родилось. Вначале должна была возникнуть константа ускорения свободного падения как некая «подлинность» в любых изменчивых обстоятельствах, и только затем в науке оказалось важным видеть, что этой постоянной, собственно, и нет (в каждом конкретном случае мы имеем множество тех самых «помех»: трение, центробежная сила в различных географических широтах, сопротивление воздушного океана и т. п.). Естествознание лишь на современном этапе своего развития (обозначаемого как постнеклассический) благодаря компьютеризации исследований имеет возможность учитывать сложную со-бытийность явления. Учет «шумов и помех» создал новую науку (см.: Глейк, 2001), в которой классическая онтологическая стратегия перестает быть условиями понятности опыта.

Таким образом, только в рамках той онтологической матрицы, которая была создана Парменидом, оказалось возможным (и даже неизбежным) появление классического естествознания. Принцип объективации и базовая интуиция идеализации - это открытие философии. Открывается пространство, в котором развивается естествознание, что и выступает важнейшим условием единства философии и науки.

Однако важно понять, что же выступает фактором дифференциации в этом онтологически едином концептуальном пространстве.

\section{ГАБИТУСЫ ЯЗЫКА: \\ СПЕЦИФИКА КОГНИТИВНОЙ ТЕХНИКИ}

Познание мира, если брать его в качестве непосредственного личного (даже интимного) процесса, - это всегда дело синкретичное. Но в качестве требований коммуникации (в том числе и внутренней) необходимым условием интеллектуальной деятельности выступает дифференциация и спецификация. М. Хайдеггер подчеркивал роль «эпистемы»как такой истины, которую возможно передать другому. Определенный экстремум этой идеи реализует Б. Аатур, показывающий, что знание обрета- 
ет ту или иную форму, когда его требуется «передать». Он настаивает на значимости не только коммуникации как таковой, но и ее материальных носителей (Аатур, 2017). Хотелось бы добавить: реализуя потребность передавать знание о мире, как говорить и писать (на чем бы то ни было), не менее важно, чем что говорить и писать.

Сегодня языковая специфика познания связывается главным образом с понятием дискурса. Но дискурс как речевую практику трудно зафиксировать - мы всегда будем иметь дело с дискурсом какой-то научной школы, лаборатории и т. п. Понимание в контексте дискурса чаще всего выступает лишь пониманием-согласием о профессиональных манипуляциях в конкретном сообществе. Поэтому при всей значимости дискурс-анализа его следует дополнять поиском других дифференцирующих агентов коммуникации.

Габитусы ${ }^{1}$ языка являются формой дифференциации и спецификации языка. Габитус также выступает принципом, порождающим определенный характер практики, но он не сводится к измерению дискурса, поскольку «останавливает» процедуру дробления. Габитусы не предполагают осознанного применения правил формообразования (что особенно подчеркивает в понятии «габитус» П. Бурдье, см.: Бурдье, 1998), но тем не менее связаны с довольно строгой регламентацией.

Язык может рассматриваться как система, включающая блоки презентативного (музыка, изобразительность и т. п.), вербального и формализованного габитусов. Габитус языка (как сказано) оказывается важнейшим условием той или иной формы «схватывания» мира. Изобразительный знак «инь - ян» и формула гармонического колебания (экстремумы «линейки габитусов») - это информация о периодичности. Однако и то, и другое сообщение при единстве содержания выступает различным когнитивным инструментарием: благодаря научной формуле мы имеем возможность «дотронуться» до конкретного события, тогда как изображение «инь - ян» повествует не меньше, чем обо всем.

В пределах вербального габитуса можно обнаружить тот же спектр функций: слово «зверь» задает возможность охвата не только реального, но и фантастического животного мира; «животное» открывает уже перспективу только реального мира; термин научной зоологической номенклатуры укажет уже на конкретный и довольно узкий сектор реального биологического разнообразия.

Наука получает пространство самоосуществления даром, как ребенок утробу матери - она рождается в том габитусе языка, который сформирован философией. Это вербальный естественный язык, связанный с логическим мышлением. Философия проделала уникальную работу: в стихии повседневной практики она находила концепты, описывающие жизненный опыт, и делала их понятиями. Вспомним о «низком происхождении» важнейших из них: материя - «строительный лес», субстанция «подстилка», сущность - «имущество» / «собственность» и т. п. Опыт такой работы с языком наследует и наука.

Однако философия и наука не смогли бы стать различными формами познания, если бы не произошло дальнейшее «расслоение» в этом языковом секторе: в науке происходит «смещение» языка в экстремум данного локуса; понятие становится термином, формируются терминосистемы. Однако и этого мало. Наука и в первую очередь естествознание - приобретает способность планировать и регулировать свою деятельность без руководства философии (!) тогда, когда получает для этого собственный, отличный уже и от философского, когнитивный инструментарий. 
Г. Галилей, сознательно применяющий метод Архимеда в противовес методу Аристотеля, видит не просто в математике, а именно в математической формуле главный инструмент работы с опытными данными. Собственно, выстраивание физического эксперимента выступает у него способом проверить правильность формулы, подобно тому как Архимед выстраивал машины, которые должны были работать так, как обещали его математические абстракции; Галилей подчеркивает, что воссоздает метод Архимеда. Габитус формулы позволяет науке реализовывать деятельную практическую стратегию. Ааже самое трепетное материнское описание конкретного ребенка не позволит выделить его среди миллионов других так, как это сделает формула его АНК. В этом габитусе языка естествознание имеет инструмент «прикосновения» к конкретному явлению и манипуляций с ним. Повторюсь однако, что габитус языка формулы развивается не где-то помимо философского (понятийного) пространства, а «внутри» него.

Конечно, каждая научная теория вырабатывает свой язык - на чем настаивает эпистемологический перспективизм / анархизм: например, П. Фейерабенд. Отсутствие общей меры помимо проблемы выбора (несопоставимости теорий), борьбы мнений и т. п. демонстрирует также проблему непонимания: ученым требуется пояснять суть своих идей, искать в пределах общего языка науки возможности уточнения и «перевода». И это может только радовать, если мы вспомним доводы Ф. Шлейермахера о приоритете непонимания во всякой герменевтической ситуации: никакой коммуникации вообще бы не было, если бы язык осуществлял перенос смысла без «потерь» или некоего остатка, связанного co Sprachnot (принципиально «невыговариваемое»). Но габитус научного языка, в отличие, например, от языка поэзии и даже языка философии, выступает такой герменевтической средой, которая минимизирует эту важную функцию непонимания - благодаря формализации.

Научное сообщество постоянно прилагает усилия, чтобы держать ситуацию неизбежной непереводимости в рамках: в самых разных формах научной коммуникации постоянно уточняются содержание и значение терминов, а попытки авторского волюнтаризма или метафорического использования научных понятий строго осуждаются. В качестве примера приведу претензии ученых в адрес философов, которые озвучили, например, А. Сокал и Ж. Брикмон (Сокал, Брикмон, 2002). Критикуя философов за некорректное использование терминов современного естествознания, они, по сути, защищают не столько сами термины («нелинейность», «фрактальность» и т. п.), сколько границы габитуса языка науки от их размывания и «возвратного» слияния науки и философии.

Таким образом, мы видим, что габитус языка - это инструмент мысли, и эти инструменты весьма различны у философии и науки. Но при этом единство философии и науки не разорвать: это онтологически единое пространство. И хотя само это пространство неоднородно (в нем реализуется локус науки), некая единая «питательная среда» проблематизации создает общие векторы движения. Онтологические трансформации как изменения условий понятности опыта - это такая форма движения, которую можно сравнить с движением тектонических плит, настолько это редкие и глобальные процессы активизации миропонимания.

\section{ОНТОАОГИЧЕСКАЯ РЕЗИСТЕНТНОСТЬ ЕСТЕСТВОЗНАНИЯ}

В научном освоении реальности опытом оказываются не все чувственные данные, но только значимые. Значимы они постольку, поскольку укладываются в определен- 
ную систему понятности, т. е. определенную онтологическую стратегию. Сам опыт, таким образом, задан определенной онтологической матрицей, остальное оказывается «невидимым». Тем самым поставляемый естествознанием опыт работает на подтверждение «единственности» фундирующей его онтологической матрицы. Эта «круговая порука» философии и естествознания выступает основанием резистентности как онтологического, так и научного содержания. Тон, повторюсь, в этих процессах задает именно философская онтологическая работа. И это повод не для торжества философии, а для ее беспокойства, поскольку определенные условия понятности позволяют нам иметь только тот образ реальности, который позволяют. Потому «тектонические сдвиги» в понимании (понятности) реальности - явления крайне редкие.

Становится понятно, почему философия современного онтологического поворота так тесно связывает науку и онтологию. Это не только поворот внимания к онтологии (непременно удерживая в поле внимания научные задачи), но в первую очередь это разворот в сторону от классической онтологии. Современная онтология предлагает новые концепты: гиперхаос, контингентность (К. Мейясу), замещающая причинность (Г. Харман) и др., а дисциплина под названием «философские проблемы естествознания» оказывается тем пространством, где проблемные точки онтологии оказываются одновременно проблемными точками естествознания. Их наличие - это не только маркеры «тупиков» мысли, но и «развилок», которые уводят мысль в укрытое невниманием, «невидимостью». Мы не можем запросто вторгаться в эту «темноту», но историческое исследование развития науки помогает лучше увидеть определенные когнитивные направляющие.

В качестве примера можно проанализировать (по необходимости кратко) становление теории великого объединения, которая по сей день развивается очень активно и... столь же активно разрывает с понятностью. Что является своего рода «точкой абсурда $»^{2}$. Теория великого объединения берет свое начало с уравнения общей теории относительности, где левая часть представляет собой тензорное полевое решение, а правая описывает материю, создающую гравитационное притяжение. В свое время А. Эйнштейна очень не устраивала именно правая часть, и он первый начал приводить уравнение к единому полевому содержанию. Т. Калуца добился объединения гравитационного и электромагнитного поля введением дополнительного пятого измерения. Затем по этому пути шел О. Клейн, истолковав это измерение как свернутую «петлю». Сегодня мы имеем 11 измерений в теории супергравитации, а иногда уравнение требует измерений числом более сотни... В самом естествознании ничего не запрещает такой ход исследования, однако неизбежны сомнения относительно репрезентативности этих теорий в смысле представления о реальности - т. е. дает сбой понятность этих теорий не в смысле доходчивости, а в смысле миропредставления. Важно видеть, что траектория мысли указанной теории лежит в области действия классической онтологической матрицы, и то, какие ограничения она накладывает. А именно: уравнение Эйнштейна имеет отношение к важнейшему для общей теории относительности принципу эквивалентности. Он возник в свое время благодаря мысленному эксперименту: для наблюдателя в закрытом пространстве (лифте) нет различия, двигается ли он с ускорением или в поле тяготения; силы инерции, вызываемые ускорением, говорит Эйнштейн, нельзя отличить от гравитационных сил. Сам этот мысленный эксперимент возможен за счет того, что нечто вытеснено в пространство «невнимания». Разумеется, Эйнштейн понимал, что ускорение лифта, движущегося вверх, требует затраты энергии и оплачивается энтропией, в отличие от движения в гравитационном 
поле. Но условия понятности той науки, в которой он работает, позволяют (и даже Аиктуют!) «вырвать» объект из созидающих его связей. В этом смысле галилеевский маятник и лифт Эйнштейна работают в одной онтологической матрице, которая рано или поздно обречена давать сбой. Она оказывается тесной для интерсубъективного познающего сознания. Что, собственно, происходит прямо сейчас.

\section{ЗАКАЮЧЕНИЕ}

Сегодня мы оказались в мире, который вновь стремится стать понятным. Онтологический поворот современной философии может быть понят не просто ее «внутренним делом», но и как проблема когнитивной «тесноты», которая острее всего ощущается современным естествознанием. Наука активно формирует новые предметные области и «прощупывает» их новыми концептами: например, такими как «нисходящая причинность», «позиционный контроль»- они крайне важны в современной экологии (см.: Большаков, Аобринский, 2002).

В современной науке актуальна теория complexity - этот термин С. Хокинга характеризует парадигму науки в XXI в. и представляет собой не просто теорию о сложном объекте, поведении и т. п., но своего рода метатеорию, выясняющую меру нередуцируемости всякой сложности. Теория complexity может быть понята как пространство обобщения новых предметных полей, поскольку эти предметы вовсе не новые, это все тот же мир, но с учетом шумов и помех. Это новое пространство эмпирии, которая, однако, сама по себе не дает условий понятности. Это работа онтологии. В рамках конкретных задач естествознания онтология может решать свои проблемы, преодолевать свои невозможности. Эти решения, в свою очередь, могут быть востребованы как условия понятности опыта и в широком, мировоззренческом, смысле, и в более узком - как опыта естественных наук.

\section{ПРИМЕЧАНИЯ}

1 Габитус - внешний вид, конституция, а также привычка, обыкновение, этос.

2 О подобном непонимании говорил Филон Александрийский, указывая на ситуации, когда верующий сталкивается в Писании с противоречивым образом Божественного. Мыслитель рекомендовал ценить эти срывы понятности и отмечал, что они требуют герменевтических сдвигов, т. е. изменения самих условий понимания (Филон Александрийский, 2000).

\section{СПИСОК АИТЕРАТУРЫ}

Большаков, В. Н., Аобринский, А. Н. (2002) Станислав Семенович Шварц. 1919-1976. М. : Наука. 123 с.

Бурдье, П. (1998) Структура, габитус, практика // Журнал социологии и социальной антропологии. Т. 1. № 2. С. 44-59.

Глейк, Аж. (2001) Хаос. Создание новой науки. СПб. : Амфора. 398 с.

Касавин, И. Т. (1998) Миграция. Креативность. Текст. Проблемы неклассической теории познания. СПб. : Русская гуманитарная христианская академия. 408 с.

Койре, А. (1985) Очерки истории философской мысли. О влиянии философских концепций на развитие научных теорий. М. : Прогресс. 288 с.

Косарева, А. М. (1997) Рождение науки из духа культуры. М. : Изд-во Института психологии РАН. 360 с.

Аатур, Б. (2017) Визуализация и познание // Аогос. Т. 27. № 2. С. 95-156.

Иебедев, С. А. (2013) Философия науки : учеб. пособие для магистров. М. : Юрайт. 288 с.

Иебедев, С. П. (2008) Идеализм: история и логика генезиса. СПб. : Изд-во СПбГУ ; ИзА-во РХГА. 827 c. 
Мамардашвили, М. К. (2002) Философские чтения. СПб. : Азбука-классика. 832 с.

Мейясу, К. (2015) После конечности: эссе о необходимости контингентности. Екатеринбург ; М. : Кабинетный ученый. 196 с.

Павлов, К. А. (2009) К тематизации понятия логики: формы познания и коммуникация // Наука: от методологии к онтологии / отв. ред. А. П. Огурцов, В. М. Розин. М. : ИФ РАН. 287 с. C. 67-97.

Парменид. (1989) О природе / Парменид ; сост. и пер. А. В. Аебедев // Фрагменты ранних греческих философов. Ч. 1: От эпических теокосмогоний до возникновения атомистики. М. : Наука (Сер.: Памятники философской мысли). 576 с.

Пикеринг, Э. (2017) Новые онтологии // Могос. Т. 27. № 3. С. 153-172.

Сокал, А., Брикмон, Ж. (2002) Интеллектуальные уловки. Критика современной философии постмодерна. М. : Аом интеллектуальной книги. 248 с.

Толорайя, Н. Б. (1991) Апейрон, или Нематериальная Вселенная Анаксимандра. М. : СП «МосПари». 51 с.

Филон Александрийский (2000). Толкования Ветхого завета. М. : Греко-латинский кабинет Ю. А. Шичалина. 456 с.

Machamer, P. A. (2002) Brief Historical Introduction to the Philosophy of Science // Philosophy of Science. Series Editor: S. M. Cahn. Malden USA; Oxford UK : Blackwell Publishers Ltd. P. 360 p. P. 1-18.

Rosenberg, A. (2005) Philosophy of Science. A contemporary introduction. Taylor \& Francis eLibrary. $225 \mathrm{p}$.

Aата поступления: 30.07.2018 2.

\section{PHILOSOPHICAL ISSUES OF NATURAL SCIENCE: \\ SEARCH FOR NEW CONDITIONS FOR THE COMPREHENSIBILITY OF EXPERIENCE \\ S. V. OBOLKINA}

Institute of Philosophy and LAW, URAL BRANCH Of the Russian ACADEMY of SCIENCES

This paper analyzes the scientific and philosophical potential of the discipline "Philosophical Issues of Natural Science". The connection between philosophy and natural science is often understood in terms of hierarchical relations, "care" attitude. The author shows the problematic nature of this understanding and reveals the problem which lays the foundations of these solutions on the basis of epistemological research. It is associated with an incorrect understanding of ontology and, therefore, the ontological foundations of natural science. It is proposed to consider ontology fundamentally not identical with the concepts of the "picture of the world", "image of reality", etc. The author draws on traditions of Russian philosophy: in the papers of M. K. Mamardashvili, V. V. Bibikhin, and others, ontology acts as the conditions of the comprehensibility of experience. This approach is close to searches in modern philosophy that considers ontological issues in the context of the study of scientific knowledge (Q. Meillassoux, G. Harman, E. Pickering, etc.).

The author analyzes the formation of the classical ontology matrix, its influence on the formation of natural science and the following limits of this approach. She proposes seeing the unity of philosophy and natural science precisely in this understanding of ontology; as an example, the Grand Unified Theory is analyzed. Also, the paper pays attention to the grounds for the differentiation between philosophy and science. A unified space of cognition of the world is interpreted as communicative, within which specification and distinction are especially important. The author suggests considering it as a system of language habitus - not only forms of differentiation, but in the first place, various cognitive tools.

This approach allows for the possibility of distinguishing between science and philosophy as different forms of cognition without losing their fundamental unity. Today, this unity manifests itself in the form of a crisis of the world comprehensibility.

Keywords: philosophy of science; natural science; epistemology; ontology; ontological turn; speculative realism; language habitus; conditions for the comprehensibility 
Bol'shakov, V. N. and Dobrinskij, L. N. (2002) Stanislav Semenovich Shvarc. 1919-1976. Moscow, Nauka Publ.123 p. (In Russ.)

Bourdieu, P. (1998) Structures, habitus, practices. Zhurnal sociologii i social'noj antropologii, vol. I, no. 2, pp. 44-59. (In Russ.)

Gleick, D. (2001) Chaos: Making a New Science. St. Petersburg, Amfora Publ. 398 p. (In Russ.)

Kasavin, I. T. (1998) Migratsiya. Kreativnost. Tekst. Problemy neklassicheskoy teorii poznaniya. St. Peterburg, Russkaya gumanitarnaya khristianskaya akademiya Publ. 408 p. (In Russ.)

Kojre, A. (1985) Ocherki istorii filosofskoj mysli. O vliyanii filosofskih koncepcij na razvitie nauchnyh teorij. Moscow, Progress. 288 p. (In Russ.)

Kosareva, L. M. (1997) Rozhdeniye nauki iz dukha kultury. Moscow, Izdatelstvo Institut psikhologii RAN Publ. 360 p. (In Russ.)

Latur, B. (2017) Visualization and Cognition. Logos, vol. 27, no. 2, pp. 95-156. (In Russ.)

Lebedev, S. A. (2013) Filosofiya nauki: ucheb. posobie dlya magistrov. Moscow, Yurajt Publ. 288 p. (In Russ.)

Lebedev, S. P. (2008) Idealizm: istoriya i logika genezisa. St. Petersburg, SPbGU; RHGA Publ. 827 p. (In Russ.)

Mamardashvili, M. K. (2002) Filosofskie chteniya. St. Peterburg, Azbuka-klassika. 832 p. (In Russ.)

Meillassoux, Q. (2015) After Finitude: An Essay On The Necessity Of Contingency. Ekaterinburg ; Moscow, Kabinetnyj uchenyj Publ. 196 p. (In Russ.)

Pavlov, K. A. (2009) K tematizacii ponyatiya logiki: formy poznaniya i kommunikaciya. In: Nauka: ot metodologii k ontologii / ed. by A. P. Ogurcov and V. M. Rozin. Moscow, IF RAN. 287 p. P. 67-97. (In Russ.)

Parmenid (1989) O prirode. In: Fragmenty rannih grecheskih filosofov. Vol. 1: Ot ehpicheskih teokosmogonij do vozniknoveniya atomistiki. Moscow, Nauka. 576 p. (In Russ.).

Pickering, A. (2017) New Ontologies. Logos, vol. 27, no. 3, pp. 153-172. (In Russ.)

Tolorajya, N. B. (1991) Apejron, ili Nematerial'naya Vselennaya Anaksimandra. Moscow, SP «MosPari» Publ. 51 p. (In Russ.)

Filon Aleksandrijskij (2000). Tolkovaniya Vethogo zaveta. Moscow, Greko-latinskij kabinet YU. A. SHichalina. 456 p. (In Russ.)

Machamer, P. A. (2002) Brief Historical Introduction to the Philosophy of Science. In: Philosophy of Science. Series Editor: S. M. Cahn. Malden USA; Oxford UK: Blackwell Publishers Ltd. P. 360. Pp. 1-18.

Rosenberg, A. (2005) Philosophy of Science. A contemporary introduction. New York, Taylor \& Francis e-Library. 225 p.

Sokal, A. and Bricmont, J. (1998) Fashionable Nonsense: Postmodern Intellectuals' Abuse of Science. Picador. New Yark. 300 p.

Submission date: 30.07.2018.

Оболкина Светлана Викторовна - кандидат философских наук, старший преподаватель кафедры философии, научный сотрудник сектора истории и философии науки Института философии и права Уральского регионального отделения Российской академии наук. Адрес: 620108, Россия, г. Екатеринбург, ул. Софьи Ковалевской, д. 16. Тел.: +7 (343) 374-33-55. Эл. адрес: Obol 2007@mail.ru

Obolkina Svetlana Viktorovna, Candidate of Philosophy, Senior Lecturer, Department of Philosophy; Research Fellow, Sector of History and Philosophy of Science, Institute of Philosophy and Law, Ural Branch of the Russian Academy of Sciences. Postal address: 16, Sofyi Kovalevskoy St., Ekaterinburg, Russian Federation, 620108. Tel.: +7 (343) 374-33-55. E-mail: Obol2007@mail.ru 